\title{
The effect of Kahoot on undergraduate student anxiety and confidence when studying statistics
}

\author{
Amanda J. Shaker, Department of Mathematics and Statistics, La Trobe University, Melbourne, \\ Australia. Email: a.shaker@latrobe.edu.au \\ Pamela S. Hurst, Department of Ecology, Environment and Evolution, La Trobe University, \\ Melbourne, Australia.Email: p.hurst@latrobe.edu.au \\ Ellen M. Marshall, Department of Engineering and Mathematics, Sheffield Hallam University, \\ Sheffield, UK. Email: ellen.marshall@shu.ac.uk
}

\begin{abstract}
Many undergraduate students are required to study statistics, but often struggle understanding concepts, lack engagement, lack confidence, or feel anxious about statistics. Kahoot is a gamebased learning platform that can be used to increase student engagement and learning through realtime quizzes. This study aimed to evaluate the use of Kahoot on improving students' experience of studying statistics in an undergraduate (year 2) course. Pre and post Likert scale questionnaires (including the Statistical Anxiety Measure - SAM) were used to collect student responses about their statistics study experience. Questions related to anxiety, confidence, and for the post quiz, additional questions on the impact of Kahoot on behavioural engagement. Post survey results indicate positive changes in students' perceptions towards studying statistics in terms of anxiety and confidence. Kahoot was shown to have a significant and positive effect on student confidence and was also linked to lowered anxiety. Despite limited data, help-seeking anxiety explained over $50 \%$ of variation in final exam performance. Further research is recommended on the effect of Kahoot on student anxiety when studying statistics, particularly as it relates to confidence and performance.
\end{abstract}

Keywords: Confidence, statistics anxiety, Kahoot.

\section{Introduction and Literature Review}

Statistics is one of the most widely taught subjects in the undergraduate curriculum and contributes to the development of important skills such as problem solving, critical reasoning and decision making (Cui et al, 2019; Dempster \& McCorry, 2009). However, for many students it is the most feared and disliked component of their studies and often seen as a necessity to progression which must be endured (Birenbaum \& Eylath, 1994; Onwuegbuzie \& Wilson, 2003; Ziedner, 1991; Nasser, 2004). In addition to the negativity surrounding the learning of statistics, it is thought that up to $80 \%$ of students suffer with situation specific statistics anxiety at some level (Onwuegbuzie \& Wilson, 2003). It is well established in the literature that low self-efficacy towards learning statistics among students is generally associated with higher levels of experienced statistics anxiety (Chamberlain et al, 2015). Statistics anxiety has been linked to poor statistics assessment performance in numerous studies, but it is the link between statistics anxiety, student attitudes and negative learning behaviours which are thought to lead to poor performance (Macher et al, 2011; Gonzalez et al, 2016; Macher et al, 2013). Anxious students often try to avoid any statistical situation including not attending/listening to lectures, not asking for help, delaying work on assessments until the last minute, persevering less on tasks, and putting little effort into learning (Macher et al, 2011; Kesici et al, 2011), which can subsequently lead to poorer performance, reinforcing a student's view that they cannot do statistics.

Although suggestions for addressing anxiety have been made, very few researchers propose or evaluate strategies to reduce anxiety. Birenbaum \& Eylath, (1994), Baloglu, (1999), Onwuegbuzie \& 
Wilson (2003), and Chew \& Dillon, (2014) summarise strategies tested in the literature which are usually based on teaching strategies rather than behavioural strategies that students can implement. Examples include improving statistical textbooks (Johnston, 1977), using humour in the classroom (Schacht \& Stewart, 1990), making more connections between concepts and real-life application (Ellman, 1991; Belli \& Seaver, 1989), and using "sleuthing" stories upon which to practice statistical analyses (D'Andrea \& Waters, 2002). Cohen (2014) discusses the importance of using games in the teaching of difficult subjects such as statistics, whilst Macheski et al. 2008 also highlight the importance of interactive classroom activities in creating a learning community and a safe, relaxed classroom environment. While there is little in the literature evaluating the use of games-based learning on either reducing statistics anxiety or increasing confidence, Schacht \& Stewart (1990) hypothesise that interactive learning environments are important in the reduction of statistics anxiety.

The use of Audience Response Systems (ARS) for teaching statistics and mathematics subjects has been described previously. For example, Ramesh (2011) evaluated the use of an ARS in undergraduate statistics modules and found an improved learning experience, as evidenced by increased attendance and engagement. Rowlett (2010) recommends the use of ARS to facilitate more active learning, whilst Wit (2003) reported many positive impacts of using an ARS in a statistics class, including student enjoyment, and the ability for students to contribute without fear of making mistakes. Fullarton et al (n.d.) introduced arsnova-click: a gamified ARS for STEM (Science, Technology, Engineering, Mathematics) courses inspired by Kahoot and designed with a focus on privacy and anonymity.

Kahoot (https://kahoot.com/) is a game-based ARS and learning platform that can be used to increase student behavioural engagement and learning through real-time quizzes. Kahoot quizzes can be played either synchronously during a live class, or asynchronously if set for "Homework". Wang \& Tahir (2020) carried out a review on the published effects of using Kahoot. Based on their findings, they concluded that Kahoot can have a positive effect on learning, classroom dynamics, motivation, concentration, and perceived learning by students. Of the 93 studies included in the review, 14 considered student anxiety, although none focused on statistics anxiety specifically. A concern of some teachers is that the use of Kahoot in the classroom may induce anxiety due to the focus on competition and time limits for answering quiz questions. However, 10 of the 14 articles reported a reduction in student anxiety (two of which included tests for statistical significance) due to factors such as facilitating more students to feel safe to participate and answer questions without fear of being judged, and the addition of humour. Only one study of the 14 reported that Kahoot could induce agitation (anxiety) (Moutinho \& Sa, 2018). Interestingly, one study (Turan \& Meral, 2018) compared Kahoot with another polling system Socrative (https://www.socrative.com/), and found there was a statistically significant difference in anxiety scores, where anxiety scores associated with Kahoot were lower.

The main aim of this study was to evaluate the impact of Kahoot on student reported levels of anxiety and confidence regarding statistics using pre-post surveys. For course students that completed both the pre and post surveys, the relationship between reduced anxiety/increased confidence and selfreported levels of behavioural engagement with lecture material was also explored. Another aim was to see if performance on the final exam was related to responses in the post survey.

\section{Method}

\subsection{Participants}

The participants of this study were undergraduate students enrolled in the second-year course Practice of Science in Semester 1 of 2020 . Most students (68\%) were enrolled in biology-based degrees, with approximately $50 \%$ of students enrolling in Practice of Science as a core course for 
their degree or major. The remaining students chose it as an elective or as a prerequisite for a thirdyear course. All 129 students enrolled in Practice of Science were invited to take part in the study and participation was voluntary.

\subsection{Course background}

This course was established in 2013 by the School of Life Sciences to provide biology students with a second-year course that encompassed experimental design and statistical concepts. The need for statistics in second year biology was identified by $3^{\text {rd }}$ year biology course coordinators who felt students had either not retained first year statistical knowledge or missed statistics prior to third year. In particular, many students did not appear confident in determining the correct statistical test to use with data collected in the field or lab. Practice of Science has always been co-taught by two different departments. Over the years the lecturing staff have changed but since 2014 one of the authors $(\mathrm{PH})$ has been involved to different extents in the experimental design component of the subject and since 2019 another author (AS) has lectured for the statistics component. In 2020 there was a single lecturer for each component (AS for statistics and $\mathrm{PH}$ for experimental design), with corresponding teams of teaching assistants for weekly workshops.

One challenge for this course has been the successful integration of the two components so that students do not perceive each as stand alone and see the link to their biology studies. Over the last two years AS and $\mathrm{PH}$ have ensured use of the same terms where there may be differences, referred to each other's lectures where applicable, and have carefully considered the sequence of learning activities and assessments. Another challenge has been delivering the statistics component to a cohort of students with a diverse range of backgrounds in quantitative skills. Some students have not studied any maths since aged 16 at secondary school, while others have first year undergraduate maths or statistics. In addition, instruction on using the statistical package SPSS is given, which some students had not encountered previously.

Assessment of experimental design concepts includes a group oral presentation, online quizzes, an ongoing group task (3-4 students per group) of designing a hypothetical experiment but with individual submission of a written summary, and half of the end of semester exam. The statistics component (termed data analysis in the course notes) is assessed via online quizzes, two assignments, and half of the end of semester exam. Linking of the two components is achieved as students are required to state the statistical test they would use for the data in their proposed experiment study and why. To lessen student anxiety around missing an online quiz and to minimize course coordinator administration regarding missed quizzes, the best five marks of the seven online quizzes was used towards a student's final grade. PH has successfully used this 'best of' approach in other subjects and gives students an element of 'choice', which may encourage a more active role in learning (Nicol, 2009) and reduce stress about the assessment (Cook, 2001).

Kahoot was typically used at the end of each statistics lecture whereby four to six multiple choice questions were asked so that students could check their comprehension of the material in that lecture. The statistics lectures were delivered face-to-face for one week at the beginning of the semester. At that point, due to COVID-19 and the associated lockdown in Melbourne, Australia, the remaining lectures were delivered asynchronously through the use of pre-recorded videos. As such, the Kahoot quizzes were adapted to also be administered asynchronously so that students could play the Kahoot game in their own time after having watched the associated lecture material. Engagement with the lecture material and the Kahoot quizzes remained similar with this format as had been seen in previous years with a fully face-to-face format. During the final week of the semester, a longer 'revision Kahoot', which included questions relating to data analysis topics throughout the semester, was administered live over Zoom. In general, although not assessed, the 
Kahoot quizzes were useful practice for the assessed online quizzes which were related to the corresponding week of statistics material.

\subsection{Data collection}

A pre-post research design was used to measure confidence and anxiety levels experienced by students at the beginning and end of the semester respectively. The post survey also included questions regarding students' perceptions of the effect of Kahoot. In addition, responses from the pre and post surveys were matched to data available from the Learning Management System including student performance. Ethical approval to carry out the research study was obtained from the university human ethics research committee.

Several subscales measuring different aspects of statistics anxiety were taken or adapted from the Statistical Anxiety Measure - SAM (Earp, 2007) and the Statistical Anxiety Rating Scale - STARS (Cruise, Cash and Bolton, 1985). Details of the items for each subscale for task anxiety (SAM, 8 items), anxiety about asking for help (STARS, 3 items) and software anxiety (adapted, 3 items) are included in the Appendix with Cronbach's alpha values. Anxiety about choosing the right technique was analysed separately. Each question asked how anxious students felt in different situations on a 7 point scale from Not at all anxious (1) to Extremely anxious (7). Confidence was also measured using 4 items (alpha $=0.89$ ), each measured on a 7-point scale from Strongly disagree (1) to Strongly agree (7) of feeling confident with choosing the right statistical test, statistical software, interpreting output, and writing a statistical report. The same questions were asked in the post survey with the addition of questions specifically asking about the impact of Kahoot on their learning, and motivation to engage.

To better understand whether changes in anxiety and confidence during the year could be directly linked to the use of Kahoot, additional questions were included in the end of semester survey, asking students to think about the impact of Kahoot on anxiety and confidence when first going through the lecture material and studying statistics generally. In each scenario, 5-point Likert scales ranging from $1 \mathrm{~A}$ lot less anxious (1) to A lot more anxious (5) for anxiety and A lot less confident (1) to A lot more confident (5) for changes in confidence due to Kahoot. For these additional questions, a 5-point scale was more suitable than a 7-point scale when considering the possible categories available in the question (see Appendices 6.1 and 6.2).

Of the 129 students who were enrolled in and completed the subject, the pre and post surveys were completed by $n=20$ and $n=9$ students respectively, and 5 of those students completed both the pre and post surveys. For students who completed both the pre and post surveys, the course final exam mark for the Data Analysis section was retrieved after students had received their final grade for the course.

\subsection{Data analysis}

Descriptive statistics were used to present overall mean pre and post anxiety and confidence scores and student responses regarding the effect of Kahoot on anxiety and confidence. The paired $t$-test was used to test whether mean changes between pre and post scores of the summary anxiety and confidence measures were significant. The Normality assumption was checked using Normal Q-Q plots and the Shapiro-Wilk test, and we note that the $t$-test has been shown to be valid even for extremely small sample sizes of $n \leq 5$ (de Winter, 2013). The Wilcoxon signed-ranked test was used to test whether the changes between pre and post anxiety and confidence scores of the single item regarding choosing the right statistical test was significant. Effect sizes were provided to measure the relative size of the changes. The Wilcoxon signed-ranked test was used to test for statistical significance of the impact of Kahoot on student learning, motivation to engage, anxiety, and 
confidence with statistics. The Spearman correlation coefficient was used to measure the strength of association between the reported impact of Kahoot on student learning, and the reported impact of Kahoot on anxiety and confidence. Linear regression was used to measure the association between student performance and statistics-related anxiety, with assumptions checked via a scatterplot of the data, and residuals versus fits and Normal Q-Q plots. Statistical analyses were carried out using $R$ version 4.1.1 ( $R$ core team, 2019).

\section{Results}

Prior to specifically examining the effect of Kahoot (Section 3.2), the pre and post anxiety and confidence data is explored (Section 3.1). Next, the relationship between behavioural engagement measures and student perception of benefit to learning is examined (Section 3.3). Lastly, how measures of anxiety, confidence, and impact of Kahoot related to student performance is described (Section 3.4).

\subsection{Overall student anxiety and confidence levels}

Figure 1 shows the mean pre and post anxiety scores and the mean pre and post confidence scores, with error bars representing 95\% confidence intervals also shown. Based on the $n=20$ and $n=9$ students who completed the pre and post surveys respectively, all mean anxiety scores showed a decrease between the two surveys, while all mean confidence scores showed an increase between the two surveys. The largest observed difference between pre and post scores for both confidence and anxiety was for choosing the right statistical test.

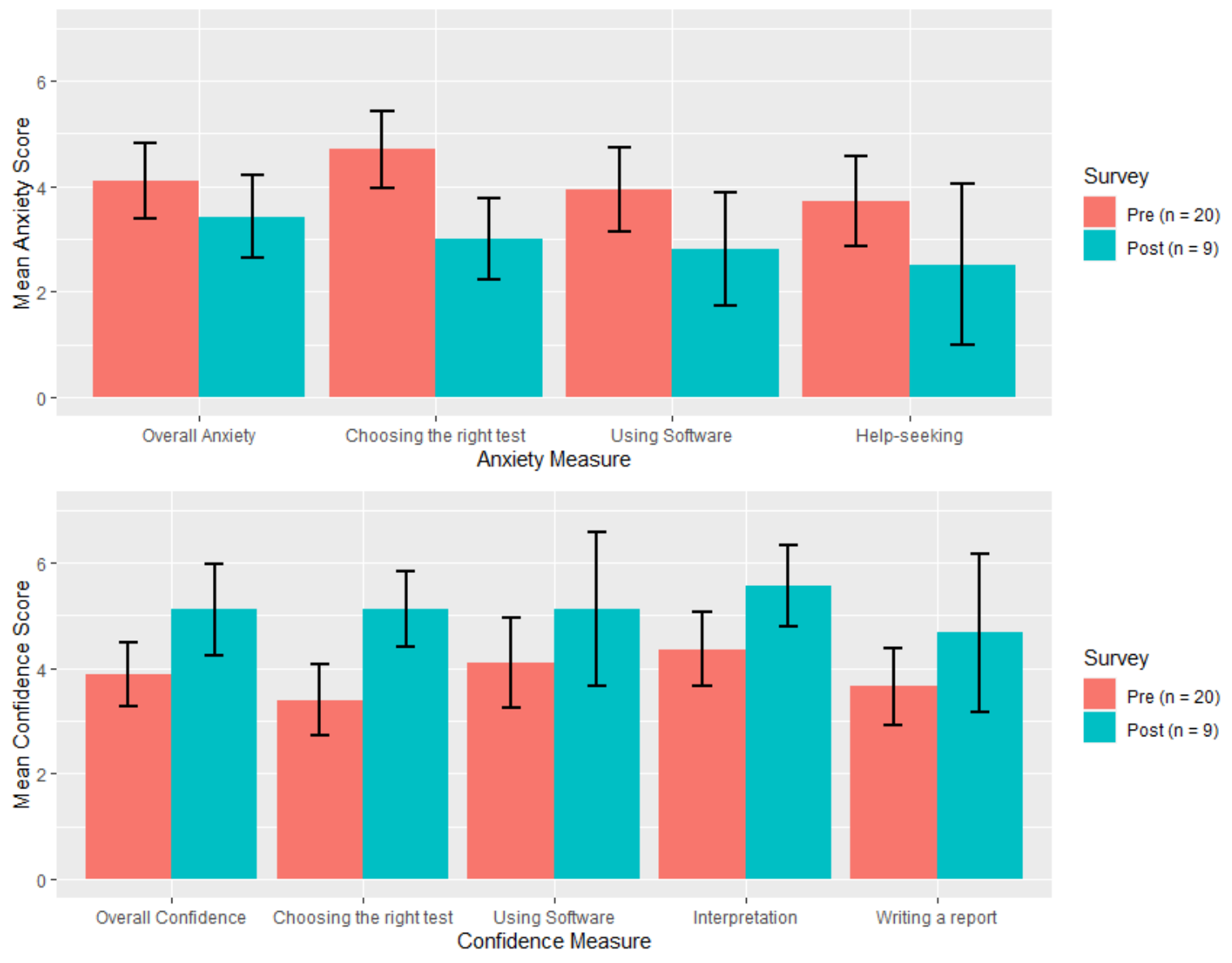

Figure 2. Mean pre and post anxiety scores (top) and confidence scores (bottom) with error bars representing $95 \%$ confidence intervals shown. 
To assess which changes were statistically significant, only the responses of the five students who completed both the pre and post survey could be used. Table 1 shows the results ( $p$-values) of the paired $t$-test, standard error, mean change, and effect size of anxiety related to using software and help-seeking, as well as the overall confidence and anxiety measures. The remaining measures listed in Figure 1 were not appropriate for a $t$-test analysis (non-Normal) and are therefore not included in Table 1. Significant results $(p<.05)$ and large effect sizes $(\mathrm{d} \geq 0.8)$ are highlighted in bold. The results indicate that, on average, the reduction in average anxiety levels based on the SAM and help-seeking anxiety measures was statistically significant. The effect size (standardised mean change) was large for all measures in Table 1 except for the Software anxiety measure, for which the measured change was zero.

Table 1. Results of paired $t$-tests $(n=5)$ for significant changes between pre and post anxiety and confidence measures, along with mean change and effect sizes. Significant $p$-values and large effect sizes are highlighted in bold.

\begin{tabular}{|c|c|c|c|}
\hline Measure & $\begin{array}{c}\text { Mean change } \\
\text { (Effect size) }\end{array}$ & Std. Error & p-value \\
\hline Anxiety about using software & $0.000(0.00)$ & 0.723 & 1.00 \\
\hline Anxiety about help-seeking & $-0.867(\mathbf{- 1 . 2 5})$ & 0.309 & $\mathbf{0 . 0 4 9}$ \\
\hline Overall statistical anxiety measure & $-0.425(\mathbf{- 1 . 2 6 )}$ & 0.151 & $\mathbf{0 . 0 4 8}$ \\
\hline Overall confidence measure & $0.900(\mathbf{0 . 8 8})$ & 0.458 & 0.12 \\
\hline
\end{tabular}

To assess the statistical significance of the changes in anxiety and confidence with regard to choosing the right test, the Wilcoxon signed-rank test was carried out. This was an important item within the context of the Practice of Science course, because developing the skill of choosing the correct statistical test is one of the main intended learning outcomes of the course. Associated Wilcoxon effect sizes were calculated where possible effect sizes can vary from $r=0$ to 1 , with an effect size of 0.5 or more considered large (Tomczak and Tomczak, 2014). The results indicated that the change in anxiety was statistically non-significant $(p=0.18)$, although the effect size was large $(r=0.76)$. The change in confidence was close-to-significant $(p=0.057)$ and the effect size was large $(r=0.91)$. Considering the small sample size $(n=5)$, these results are encouraging and indicate that by the end of the course, students seemed to become more confident and less anxious regarding choosing the correct statistical test. This indicates that consideration of these items in a larger study would be beneficial.

\subsection{Impact of Kahoot on student confidence and anxiety}

To assess the impact of Kahoot on student confidence and anxiety, at the end of semester students were asked to indicate how their confidence and anxiety was affected due to the use of Kahoot, with regard to going through the lecture material for each topic, and studying statistics generally. The impact on confidence and anxiety was measured on a 5-point likert scale. The results are shown in Figure 2, which includes the responses of the $n=9$ students who completed the post survey. With regard to anxiety related to both items, almost all students reported either no change (yellow) or less anxiety (green). One student reported more anxiety (orange). With regard to confidence related to both items, most students reported an increase in confidence due to the use of Kahoot, with either 1 or 2 students reporting no change, and one student reporting a decrease in confidence. 

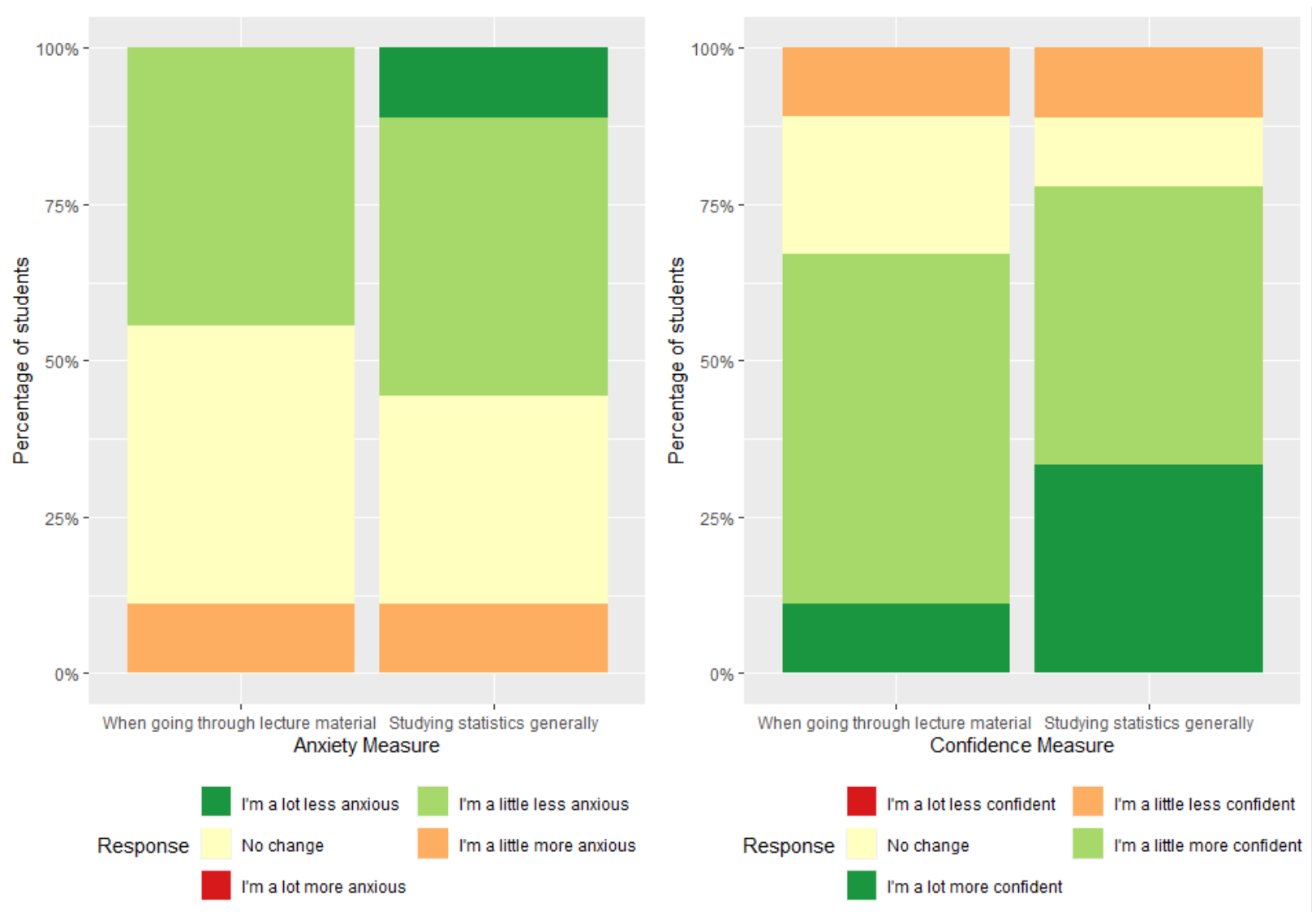

Figure 3. Student responses regarding the effect of Kahoot on anxiety (left) and confidence (right). Positive impact (less anxious or more confident) represented by green colours.

Willcoxon signed-rank tests were carried out to test the reported impact of Kahoot on student confidence and anxiety, testing whether the true median is different from 3 (no change). The results for these tests based on the $n=9$ responses are shown in Table 2, which shows $p$-values, estimated median values, and effect sizes. Significant results $(p<.05)$ and large effect sizes $(r \geq$ $0.5)$ are highlighted in bold. Students reported that Kahoot had a positive, large and statistically significant impact on their confidence studying statistics generally, and a positive, large and closeto-significant impact on their confidence when first going through the lecture material for each topic. The reductions in anxiety as a result of Kahoot were not statistically significant, however the effect size for studying statistics generally was large $(r=0.56)$, and moderate $(r=0.45)$ for going through the lecture material for each topic. Again, considering the small sample size $(n=9)$, these results are encouraging and indicate that Kahoot can have a positive effect in terms of student confidence and anxiety while studying statistics. This indicates a larger study considering these effects would be of benefit. 
Table 2. Results of Wilcoxon signed-rank tests $(n=9)$ for whether the true median effect of Kahoot on anxiety and confidence measures is different from 3 (no change). Median values and effect sizes are displayed. Significant $p$-values and large effect sizes are highlighted in bold.

\begin{tabular}{|c|c|c|c|c|}
\hline \multirow{2}{*}{ Question } & \multicolumn{2}{|c|}{$\begin{array}{c}\text { Anxiety } \\
1=\text { I'm a lot less anxious, } \\
5=\text { I'm a lot more anxious }\end{array}$} & $\begin{array}{c}\text { Confidence } \\
1=\text { I'm a lot less confident, } \\
5=\text { I'm a lot more confident }\end{array}$ \\
\hline & $\begin{array}{c}\text { Median value } \\
\text { (Effect size) }\end{array}$ & p-value & $\begin{array}{c}\text { Median value } \\
\text { (Effect size) }\end{array}$ & p-value \\
\hline $\begin{array}{c}\text { When first going through the } \\
\text { lecture material for each topic }\end{array}$ & $3(0.45)$ & 0.23 & 4 (0.638) & 0.071 \\
\hline $\begin{array}{c}\text { Studying statistics in this } \\
\text { subject generally }\end{array}$ & $2(\mathbf{0 . 5 6 )}$ & 0.12 & 4 (0.728) & $\mathbf{0 . 0 3 6}$ \\
\hline
\end{tabular}

\subsection{The relationship between Kahoot's impact on learning and engagement, and its impact on statistics anxiety and confidence}

In addition to the questions asking about the impact of Kahoot on anxiety and confidence, two questions were added to the 7-point agreement scale questions in the post survey. The items were Kahoot helped motivate me to engage more with the lecture content and Kahoot worked well in helping me learn (see Appendix 6.3). Willcoxon signed-rank tests were carried out to test the reported impact of Kahoot on motivation to engage and learning, testing whether the true median is different from 4. Associated Wilcoxon effect sizes were calculated where possible effect sizes can vary from $r=0$ to 1 , with an effect size of 0.5 or more considered large (Tomczak and Tomczak, 2014). The $n=9$ students who completed the post survey reported that Kahoot had a positive, large, and close-to-significant impact on engagement with lecture content $(p=0.10, r=0.56)$ and learning ( $p=0.093, r=0.58)$, with a median score of 6 for both measures. An analysis of the Spearman correlation between these two items yielded some interesting results. In particular, there was a perfect and highly significant correlation $(1, p<.001)$ between the agreement scores of these items. This would seem to indicate that student behavioural engagement and student perception of learning are linked.

Also of interest was the observed relationship between the item Kahoot worked well in helping me learn (and by default Kahoot helped motivate me to engage more with the lecture content) and the effect of Kahoot on anxiety and confidence. The sample Spearman correlations are provided in Table 3 , which shows significant, strong, negative associations between the impact of Kahoot on learning and on anxiety, and highly significant, very strong, positive associations between the impact of Kahoot on learning and on confidence. Recalling the results in the previous section, the effect of Kahoot on anxiety was not significant. However, the impact of Kahoot on items related to confidence and perceived learning were all positive and either significant or close-to-significant. The highly significant and strong, positive associations between the reported effect of Kahoot on student learning and confidence shown in Table 3 therefore indicate that Kahoot has had a positive impact on perceived student confidence and student learning overall, although the presence and direction of causation is unclear. 
Table 3. Sample Spearman correlations between the reported impact of Kahoot on learning, and the reported impact of Kahoot on measures relating to anxiety and confidence.

\begin{tabular}{|c|c|c|c|c|}
\hline & \multicolumn{2}{|c|}{$\begin{array}{c}\text { Reported impact of Kahoot on } \\
\text { anxiety }\end{array}$} & \multicolumn{2}{c|}{$\begin{array}{c}\text { Reported impact of Kahoot on } \\
\text { confidence }\end{array}$} \\
\hline & $\begin{array}{c}\text { When going } \\
\text { through the } \\
\text { lecture material } \\
\text { for each topic }\end{array}$ & $\begin{array}{c}\text { Studying } \\
\text { statistics in this } \\
\text { subject generally }\end{array}$ & $\begin{array}{c}\text { When going } \\
\text { through the } \\
\text { lecture material } \\
\text { for each topic }\end{array}$ & $\begin{array}{c}\text { Studying } \\
\text { statistics in this } \\
\text { subject generally }\end{array}$ \\
\hline $\begin{array}{c}\text { Kahoot worked } \\
\text { well in helping } \\
\text { me learn }\end{array}$ & $-0.75^{\star}$ & $-0.64^{*}$ & $0.82^{\star *}$ & $0.88^{\star * *}$ \\
\hline
\end{tabular}

p-values $(0,0.001,0.01,0.05,0.1,1)<=>$ symbols(“***”. “**”, “*”, “.”, " “)

\subsection{Relationship to student performance}

Linear regression modelling was carried out to assess the relationship between student performance on the exam, and all items related to anxiety, confidence and the impact of Kahoot. Most items were not found to be significantly associated with student performance, although this may be partially due to the limitation of a small sample size $(n=9)$. However, despite the small sample size, anxiety associated with asking for help was significantly associated with student performance based on responses from both the pre and post surveys. The result from the post survey data is reported here: in particular, a simple linear regression analysis was conducted to test the association between exam mark as the response, and the anxiety measure for Asking one of my statistics teaching staff for help in understanding computer output as the predictor. The results of the regression indicated that helpseeking anxiety explained $52.39 \%$ of the variation in exam marks $\left(R^{2}=.5239, F(1,7)=7.704, p=\right.$ .028). Help-seeking anxiety score is a significant predictor of exam mark $(\beta=-3.683, p=.028)$. For each additional point in help-seeking anxiety score, on average, exam mark was between 0.55 and 6.82 marks lower. This finding indicates that help-seeking anxiety and ways it can be addressed warrants further research.

\section{Discussion, conclusions, and future work}

The results indicate positive, large, and some significant (or close-to-significant) changes in both student confidence and statistics-related anxiety when comparing pre and post scores. The results further indicate that Kahoot can have a positive impact on student confidence and student engagement \& learning, and further that the impact of Kahoot on these aspects are correlated. Although the effect of Kahoot on anxiety was positive, the results were not as strong as the effect of Kahoot on confidence. Considering possible reasons for this, anecdotal evidence suggests that timed testing can be anxiety-inducing or affect performance for some students [this has also been seen in the literature; e.g. Onwuegbuzie \& Seaman (1995)], but that this may not necessarily inhibit increases in confidence. For instance, consider one student's response in the post survey to the question, What else (if anything) has helped reduce your anxiety about studying statistics this semester?: "Most of my anxiety is around timed testing...". This student also responded that Kahoot had a positive impact on motivation to engage, learning, and confidence, but no change to anxiety. Although the negative association between statistics anxiety and student performance is documented in the literature (Chew \& Dillon, 2014), Keeley et al., (2008) found that very high or very low levels of anxiety were associated with lower performance, while mid-range anxiety was associated with higher performance. They argued against assuming that lengths should be taken to eliminate all anxiety, while Onwuegbuzie \& Wilson (2003) suggested that some statistics anxiety can even be facilitative rather than debilitative when not experienced in extreme measures. Hence, it 
may be argued that some anxiety may be acceptable when associated with playing Kahoot, particularly if at the same time it is a confidence-building exercise that facilitates better learning.

Still, Wang \& Tahir (2020) summarise some useful suggestions that can help to reduce student anxiety, one of which is that students can be anonymous while playing Kahoot by using nicknames, which can lead to reduced stress and creation of a safer environment within which to fail. To reduce the potential fear of losing Kahoot games, Wang \& Tahir (2020) report that playing Kahoot as teams rather than individuals has been suggested. Another obvious suggestion for the anxiety some students experience around pressure to answer questions quickly is to increase the time allowed to answer questions, although this may not always be possible within the time constraints of a class. At present, the possible time that can be allowed for answering a question ranges from 5 seconds to 4 minutes. Verbal feedback from students about the assessed online quizzes indicated that students greatly appreciated the long timeframe ( 2 hours) within which to complete them, perceived that they were helpful for learning, and were useful for staying on track with course content; observations which warrant further research into the use of online quizzes to facilitate learning and reduce statistics anxiety.

The obvious association observed between anxiety related to help-seeking and student performance is an observation that also warrants further investigation. These preliminary results indicate that a future workshop based on statistics-related anxiety (see, e.g. Marshall et al, 2017), with a particular focus on the benefits of help-seeking, along with strategies to normalise help-seeking in the curriculum, may have a positive impact on student performance.

A limitation of this study is the limited sample size and associated low response rate, which may have increased the risk of self-selection bias. Still, this study has led to some interesting observations that warrant further investigation. Recommendations for further research are therefore as follows:

1. A repeat of this study but with a higher sample size, so that findings can be generalised with greater certainty;

2. Research into the reasons why Kahoot helped increase confidence or reduce anxiety, where this has occurred;

3. A study on statistics anxiety workshops that have a particular focus on help-seeking, along with strategies in the curriculum to encourage and normalise help seeking, including measurement of the impact on student performance;

4. A study on online tests with generous time-limits that can be repeated as a confidencebuilding strategy, measuring the impact on anxiety, confidence, and performance.

\section{Acknowledgements}

The authors wish to thank the editor and referees, whose valuable comments led to an improved version of this article.

\section{Appendix}

\subsection{Statistics anxiety scales}

All statistics anxiety measures contained items asking how anxious students felt in the specific situation from 1 (Not at all anxious) to 7 (Extremely anxious). The same scales were used in the pre and post surveys. 


\begin{tabular}{|c|c|}
\hline $\begin{array}{l}\text { Scale and Cronbach's } \\
\text { alpha (post survey) }\end{array}$ & Individual items \\
\hline & Statistical task anxiety \\
\hline \multirow{9}{*}{$\begin{array}{l}\text { Statistical anxiety measure } \\
\text { (Earp, 2007) } \\
\text { Cronbach's alpha }=0.94\end{array}$} & Sitting an exam in person on campus \\
\hline & Studying statistics generally \\
\hline & Reading statistical studies \\
\hline & Calculating probabilities \\
\hline & Formulating and testing hypotheses \\
\hline & Developing conclusions based on mathematical solutions \\
\hline & Interpreting statistics \\
\hline & Explaining your statistical findings \\
\hline & Software anxiety \\
\hline \multirow{4}{*}{$\begin{array}{l}\text { Created by Marshall as } \\
\text { existing scales do not contain } \\
\text { items relating to software } \\
\text { Cronbach's alpha }=0.89 \\
\end{array}$} & Inputting/manipulating data in statistical software \\
\hline & Using statistical software to carry out analyses \\
\hline & Summarising results from the statistical software output \\
\hline & Fear of asking for help \\
\hline \multirow{3}{*}{$\begin{array}{l}\text { Statistical Anxiety Rating } \\
\text { Scale - STARS (Cruise, Cash } \\
\text { and Bolton, 1985) } \\
\text { Cronbach's alpha }=0.9\end{array}$} & $\begin{array}{l}\text { Going to my statistics lecturer for individual help with material I am havin } \\
\text { difficulty understanding }\end{array}$ \\
\hline & Asking a statistics lecturer for help understanding computer output \\
\hline & Asking a fellow student for help in understanding statistics material \\
\hline
\end{tabular}

In order to ascertain whether changes in anxiety related specifically to the use of Kahoot, some additional questions were added to the post survey.

\begin{tabular}{|l|l|l|l|l|l|}
\hline $\begin{array}{l}\text { How has using Kahoot in this } \\
\text { subject impacted on any } \\
\text { anxiety you may have had } \\
\text { about Statistics? }\end{array}$ & $\begin{array}{c}\text { I'm a } \\
\text { lot less } \\
\text { anxious }\end{array}$ & $\begin{array}{c}\text { I'm a little less } \\
\text { anxious }\end{array}$ & $\begin{array}{c}\text { No } \\
\text { change }\end{array}$ & $\begin{array}{c}\text { I'm a little } \\
\text { more } \\
\text { anxious }\end{array}$ & $\begin{array}{c}\text { I'm a } \\
\text { lot } \\
\text { more } \\
\text { anxious }\end{array}$ \\
\hline $\begin{array}{l}\text { When first going through the } \\
\text { lecture material for each topic }\end{array}$ & & & & & \\
\hline $\begin{array}{l}\text { Studying statistics in this } \\
\text { subject generally }\end{array}$ & & & & & \\
\hline
\end{tabular}

\subsection{Statistics confidence scales}

Students were asked how much they agreed with the following questions about confidence with key aspects of statistics on a 7 point scale from 1 (Strongly disagree) to 7 (Strongly agree).

\begin{tabular}{|l|l|}
\hline \multirow{3}{*}{$\begin{array}{c}\text { Statistical confidence } \\
\text { Cronbach's alpha }=\mathbf{0 . 8 9}\end{array}$} & I feel confident choosing the right statistical test \\
\cline { 2 - 2 } & I feel confident interpreting results from statistical software \\
\cline { 2 - 2 } & I feel confident using the statistical software taught on my course \\
\cline { 2 - 2 } & I feel confident writing a statistical report \\
\hline
\end{tabular}


In order to ascertain whether changes in confidence related specifically to the use of Kahoot, some additional questions were added to the post survey.

\begin{tabular}{|l|l|l|l|l|l|}
\hline $\begin{array}{l}\text { How has using Kahoot in this } \\
\text { subject impacted on any } \\
\text { confidence you may have had } \\
\text { about Statistics? }\end{array}$ & $\begin{array}{c}\text { I'm a lot } \\
\text { less } \\
\text { confident }\end{array}$ & $\begin{array}{c}\text { I'm a little } \\
\text { less } \\
\text { confident }\end{array}$ & $\begin{array}{c}\text { No } \\
\text { change }\end{array}$ & $\begin{array}{c}\text { I'm a little } \\
\text { more } \\
\text { confident }\end{array}$ & $\begin{array}{c}\text { I'm a lot } \\
\text { more } \\
\text { confident }\end{array}$ \\
\hline $\begin{array}{l}\text { When first going through the } \\
\text { lecture material for each topic }\end{array}$ & & & & & \\
\hline $\begin{array}{l}\text { Studying statistics in this } \\
\text { subject generally }\end{array}$ & & & & & \\
\hline
\end{tabular}

\subsection{Additional questions measuring impact of Kahoot}

Students were asked in the post survey how much they agreed with the following questions about the impact of Kahoot on a 7 point scale from 1 (Strongly disagree) to 7 (Strongly agree).

Engagement and learning

Kahoot helped motivate me to engage more with the lecture content

Kahoot worked well in helping me learn

\section{References}

Baloglu, M., 1999. A comparison of mathematics anxiety and statistics anxiety in relation to general anxiety. [pdf] ERIC. Available at: http://files.eric.ed.gov/fulltext/ED436703.pdf [Accessed 20 May 2021].

Belli, G.M. and Seaver, W.L., 1989. Graduate statistics service courses in part-time off-campus programs. The American Statistician, 43(2), pp.86-90.

Birenbaum, M. and Eylath, S., 1994. Who is afraid of statistics? Correlates of statistics anxiety among students of educational science. Educational Research, 36(1), pp.93-98.

Chamberlain, J.M., Hillier, J. and Signoretta, P., 2015. Counting better? An examination of the impact of quantitative method teaching on statistical anxiety and confidence. Active Learning in Higher Education, 16(1), pp.51-66. https://doi.org/10.1177\%2F1469787414558983

Chew, P.K.H. and Dillon, D.B., 2014. Statistics anxiety update: Refining the construct and recommendations for a new research agenda. Perspectives on Psychological Science, 9(2), pp.196208. https://doi.org/10.1177/1745691613518077.

Cohen, R.L., 2014. Playing with numbers: Using Top Trumps as an ice-breaker and introduction to quantitative methods. Enhancing Learning in the Social Sciences, 6(2), pp.21-29.

Cook, A., 2001. Assessing the use of flexible assessment. Assessment \& Evaluation in Higher Education, 26(6), pp.539-549.

Cui, S., Zhang, S., Guan, D., Zhao, X. and Si, J., 2019. Antecedents of statistics anxiety: An integrated account. Personality and Individual Differences, 144(2019), pp.79-87. 
D'Andrea, L. and Waters, C., 2002. Teaching statistics using short stories: Reducing anxiety and changing attitudes. In ICOTS 6 The Sixth International Conference on Teaching Statistics "Developing a Statistically Literate Society". Cape Town, South Africa, 7-12 July 2002 [online] Available at: http://iase-web.org/documents/papers/icots6/8a2 dand.pdf [Accessed 18 May 2021].

de Winter, J.C.F., 2013. Using the Student's t-test with extremely small sample sizes. Practical Assessment, Research, and Evaluation, [e-journal] 18(Article 10). https://doi.org/10.7275/e4r6-dj05.

Dempster, M. and McCorry, N.K, 2009. The role of previous experience and attitude towards statistics in statistics assessment outcomes among undergraduate psychology students. Journal of Statistics Education, [online] Available at: http://jse.amstat.org/v17n2/dempster.html [Accessed 20 May 2021].

Earp, M., 2007. Development and validation of the Statistics Anxiety Measures. Ph.D. University of Denver.

Ellman, J.S., 1991. An elaboration approach to teach statistics: Its effects on math anxiety, attitude, and achievement. Ph.D. University of South Dakota.

Fullarton, C.M., Hoeck, T.W. and Quibeldey-Cirkel, K., 2017. arsnova.click - A game-based audience-response system for STEM courses. Available at: https://arsnovauploads.mni.thm.de/Demo-Kartei/arsnova-click EDULEARN17.pdf [Accessed 20 May 2021].

González, A., Rodríguez, Y., Faílde, J.M. and Carrera. M.V., 2016. Anxiety in the statistics class: Structural relations with self-concept, intrinsic value, and engagement in two samples of undergraduates. Learning and Individual Differences, 45(2016), pp.214-221. http://dx.doi.org/10.1016/j.lindif.2015.12.019.

Johnston, A.G., 1977. Social Statistics without Tears. New York: McGraw-Hill Companies.

Keeley, J., Zayac, R. and Correia, C., 2008. Curvilinear relationships between statistics anxiety and performance among undergraduate students: Evidence for optimal anxiety, Statistics Education Research Journal, [e-journal] 7(1). Available at: http://iaseweb.org/documents/SERJ/SERJ7(1) Keeley.pdf [Accessed 20 May 2021].

Kesici, S., Baloğlu, M. and Deniz, M., 2011. Self-regulated learning strategies in relation with statistics anxiety. Learning and Individual Differences, 21(4), pp.472-477. http://dx.doi.org/10.1016/..lindif.2011.02.006.

Macher, D., Paechter, M., Papousek, I. and Ruggeri, K., 2011. Statistics anxiety, trait anxiety, learning behaviour, and performance. European Journal of Psychology of Education, [online] Available at: https://www.jstor.org/stable/43551094 [Accessed 20 May 2021].

Macher, D., Paechter, M., Papousek, I., Ruggeri, K., Freudenthaler, H.H. and Arendasy, M., 2013. Statistics anxiety, state anxiety during an examination, and academic achievement. British Journal of Educational Psychology, 83(4), pp.535-549.

Macheski, G.E., Buhrmann, J., Lowney, K.S. and Bush, M.E., 2008. Overcoming student disengagement and anxiety in theory, methods, and statistics courses by building a community of learners. Teaching Sociology, 36(1), pp.42-48.

Marshall, E.M., Wilson, D.A. and Mann, V.E., 2017. Addressing maths anxiety and engaging students with maths within the curriculum. MSOR Connections, [e-journal] 15(3), Available at: https://journals.gre.ac.uk/index.php/msor/article/view/555 [Accessed 20 May 2021]. 
Moutinho, A. and Sá, S., 2018. Implementing active learning through pedagogical coaching in Control Systems lectures. In 2018 3rd International Conference of the Portuguese society for Engineering Education (CISPEE) Aveiro, Portugal, 27-29 June, IEEE [online] Available at http://latrobe.edu.au/library [Accessed 20 May 2021].

Nasser, F.M., 2004. Structural Model of the effects of cognitive and affective factors on the achievement of Arabic speaking pre-service teachers in introductory statistics. Journal of Statistics Education, [e-journal] 12(1). https://doi.org/10.1080/10691898.2004.11910717.

Nicol, D., 2009. Quality enhancement themes: the first year experience: transforming assessment and feedback: enhancing integration and empowerment in the first year, [online] Available at: http://dera.ioe.ac.uk/id/eprint/11605 [Accessed 20 May 2021].

Onwuegbuzie, A.J. and Seaman, M.A., 1995. The effect of time constraints and statistics test anxiety on test performance in a statistics course. The Journal of Experimental Education, 63(2), pp.115124.

Onwuegbuzie, A. J. and Wilson, V. A., 2003. Statistics anxiety: nature, etiology, antecedents, effects, and treatments: a comprehensive review of the literature. Teaching in Higher Education, 8(2), pp.195-209.

R Core Team, 2019. R: A language and environment for statistical computing. (R-4.1.1). [computer program] R Foundation for Statistical Computing, Vienna, Austria.

Ramesh, N.I., 2011. Impact of audience response system in first year statistics lessons: click or not to click. MSOR Connections, 11(2), pp.29-31.

Rowlett, P., 2010. Ask the audience (yes, all of them). MSOR Connections, 10(1), pp.3-5.

Schacht, S. and Stewart, B.J., 1990. What's funny about statistics? A technique for reducing student anxiety. Teaching Sociology, 18(1), 52-56.

Tomczak, M. and Tomczak, E., 2014. The need to report effect size estimates revisited. An overview of some recommended measures of effect size. Trends in Sport Sciences, [online] Available at: http://www.tss.awf.poznan.pl/files/3 Trends Vol21 2014 no1 20.pdf [Accessed 20 May 2021]

Turan, Z. and Meral, E., 2018. Game-Based versus to Non-Game-Based: The Impact of Student Response Systems on Students' Achievements, Engagements and Test Anxieties. Informatics in Education, 17(1), pp.105-116.

Wang, A.I. and Tahir, R., 2020. The effect of using Kahoot! for learning - A literature review. Computers \& Education. Available at http://latrobe.edu.au/library [Accessed 20 May 2021].

Wit, E., 2003. Who wants to be... The use of a personal response system in statistics teaching. MSOR connections, 3(2), pp.14-20.

Zeidner, M., 1991. Statistics and mathematics anxiety in social science students - some interesting parallels. British Journal of Educational Psychology, 61(3), pp.319-328. 